\title{
Consequences of comparability
}

\author{
Cian Dorr ｜ Jacob M. Nebel | Jake Zuehl
}

Cian Dorr

Email: cd50@nyu.edu

Jacob M. Nebel

Email:jnebel@usc.edu

Jake Zuehl

Email:jz787@nyu.edu

We defend three claims about preference, credence, and choice. First, all agents (not just rational ones) have complete preferences. Second, all agents (again, not just rational ones) have real-valued credences in every proposition in which they are confident to any degree. Third, there is almost always some unique thing we ought to do, want, or believe.

These claims may seem absurd. But as we will show, they follow from certain hard-to-resist premises by a principle of the logic of comparatives that we call Comparability. This principle requires, to a first approximation, that if two things are not equally $F$, then one must be more $F$ than the other. Although many philosophers have rejected Comparability, it is widely assumed in the semantics literature on gradable adjectives and other comparative expressions. In a companion paper (Dorr, Nebel, and Zuehl 2021) we defend its validity. In the present paper, we take Comparability for granted and use it to argue for further controversial conclusions. Of course, those who reject these conclusions may prefer to read the present paper as providing a further battery of modus tollens arguments to back up the putative counterexamples that have already convinced so many philosophers to reject Comparability. But we argue, in each case, that the consequences of Comparability are less implausible than they might initially seem.

We provide the necessary background in section 1 . The rest of the paper draws out our central claims for preference, credence, and choice.

\section{1 | COMPARATIVES AND COMPARABILITY}

Comparative constructions include, paradigmatically, the comparative forms of adjectives ('more $F$ ' or ' $F$-er') and the equative form ('[at least] as $F$ as'). We are concerned with the logic of such constructions. Here are some examples of valid schemas involving comparative constructions:

Strict Comparison $x$ is more $F$ than $y$ if and only if $x$ is at least as $F$ as $y$ and $y$ is not at least as $F$ as $x$.

Equality $x$ and $y$ are equally $F$ if and only if $x$ is at least as $F$ as $y$ and $y$ is at least as $F$ as $x$. 
Restricted Reflexivity If $x$ is at least as $F$ as $y$ or $y$ is at least as $F$ as $x$, then $x$ is at least as $F$ as $x$.

Transitivity If $x$ is at least as $F$ as $y$ and $y$ is at least as $F$ as $z, x$ is at least as $F$ as $z$.

We assume that these schemas are valid for all comparative constructions in English. This does not mean of course that we are somehow prohibited from introducing novel expressions of the form 'more $F$ than' or 'at least as $F$ as' in ways that violate these schemas. Such deviant uses fall outside the scope of the principles. The arguments of this paper only require the schemas to hold for a few familiar comparatives, which we will encounter later on.

In Dorr, Nebel, and Zuehl (2021), we argue that the following, more controversial schema is also valid:

Comparability If $x$ is at least as $F$ as $x$ and $y$ is at least as $F$ as $y$, then either $x$ is at least as $F$ as $y$ or $y$ is at least as $F$ as $x$.

Given Strict Comparison and Equality, the consequent of Comparability is equivalent to the claim that either $x$ and $y$ are equally $F$ or one is more $F$ than the other. And, given Restricted Reflexivity, the antecedent is equivalent to the claim that each of $x$ and $y$ is either at least as $F$ as something or such that something is at least as $F$ as it. ${ }^{1}$ In combination with the other principles above, Comparability moreover implies the validity of the following closely related principle, which will be used in the arguments of section 2 and 3 :

Negative Transitivity If $x$ is not more $F$ than $y$ and $y$ is not more $F$ than $z$ and $y$ is at least as $F$ as $y$, then $x$ is not more $F$ than $z .^{2}$

In Dorr, Nebel, and Zuehl (2021), we argue that the validity of Comparability provides the best explanation of the good standing of a range of seemingly impeccable patterns of inference, such as the following:

(1) If Grana Padana isn't as good as Parmesan, then Parmesan is better than Grana Padana.

(2) If algebra is no more difficult than geometry, then geometry is at least as difficult as algebra.

(3) If Sue's invention is useful and Lou's isn't, then Sue's invention is more useful than Lou's.

(4) If the lasagna is extremely tasty and the ravioli isn't, then the lasgana is tastier than the ravioli.

(5) If Descartes is one of the five most influential early modern philosophers and Malebranche isn't, then Descartes is more influential than Malebranche.

We refer the interested reader to Dorr, Nebel, and Zuehl (2021) for the details. ${ }^{3}$

Our sense is that most philosophers who have considered Comparability have maintained that it is invalid. Many supposed counterexamples have been offered, in which we are presented with a pair of items each of which is in some respects more $F$ than the other and invited to judge that neither is at least as $F$ as the other (overall), or presented with a trio of items of which we are invited to judge that the third is more $F$ than the first although the second is neither more $F$ than the first nor less $F$ than the third (although still as $F$ as itself). We find the relevant judgments quite tendentious. As we argue in Dorr, Nebel, and Zuehl (2021), many of them turn on being insufficiently cautious about vagueness, asserting ' $x$ is not at least as $F$ as $y$ ' when all that is really warranted is something like ' $x$ is not definitely at least as $F$ as $y$ ' (see also Broome 1997; Gustafsson 2013; 
Elson 2017; Williams 2016; Bronsther 2019). Moreover, some of the supposed counterexamples trade on an illegitimate switch from a "coarse-grained" context, on which 'equally $F$ ' applies to many pairs of things, to a "fine-grained" context, in which the conditions for 'equally $F$ ' to apply are extremely demanding. Overall, we believe that philosophers have failed to appreciate the great force of the appearances of validity which support Comparability, in comparison to which the alleged counterexamples seem quite weak.

The stakes of this debate are high. Opponents of Comparability have taken its supposed failures to have important implications in epistemology, decision theory, axiology, and other areas of philosophy. In this paper, we raise the stakes further by arguing that the truth of Comparability has surprising and philosophically interesting consequences concerning preference, credence, and choice: that, necessarily, everyone has complete preferences and real-valued credences, and that there is almost always some unique thing we ought to do.

Most of our arguments in this paper do not appeal directly to Comparability as stated above, but rather to natural syntactic generalizations of it. For there are grammatical kinds other than adjectives that enter into comparative constructions (Wellwood 2019): nouns ('more butter'), verbs ('swam more'), and adverbs ('better explained'). Each of the schemas listed above, including Comparability, has obvious analogues for these other categories. Rather than writing them all out, we will harmlessly treat their instances as if they were instances of the schemas stated using adjectives. Our case for the validity of Comparability carries over naturally, for example, to the following honorary instances, which respectively use a noun ('reason'), a verb ('like'), and an adverb ('virtuously'):

(6) If $x$ has at least as much reason to $\phi$ as $x$ has to $\phi$, and $x$ has as least as much reason to $\psi$ as $x$ has to $\psi$, then either $x$ has at least as much reason to $\phi$ as $x$ has to $\psi$ or $x$ has at least as much reason to $\psi$ as $x$ has to $\phi$.

(7) If $x$ likes $x^{\prime}$ at least as much as $x$ likes $x^{\prime}$ and $y$ likes $y^{\prime}$ at least as much as $y$ likes $y^{\prime}$, then either $x$ likes $x^{\prime}$ at least as much as $y$ likes $y^{\prime}$ or $y$ likes $y^{\prime}$ at least as much as $x$ likes $x^{\prime}$.

(8) If $x$ acted at least as virtuously as $x$ acted, and $y$ acted at least as virtuously as $y$ acted, then either $x$ acted at least as virtuously as $y$ acted, or $y$ acted at least as virtuously as $x$ acted.

Comparability also generalizes easily to adjectives with internal arguments, such as

(9) If $x$ is at least as similar to $x^{\prime}$ as $x$ is to $x^{\prime}$ and $y$ is at least as similar to $y^{\prime}$ as $y$ is to $y^{\prime}$, then either $x$ is at least as similar to $x^{\prime}$ as $y$ is to $y^{\prime}$ or $y$ is at least as similar to $y^{\prime}$ as $x$ is to $x^{\prime}$.

(10) If $x$ is at least as confident that $P$ as $x$ is that $P$, and $y$ is at least as confident that $Q$ as $y$ is that $Q$, then either $x$ is at least as confident that $P$ as $y$ is that $Q$, or $y$ is at least as confident that $Q$ as $x$ is that $P$.

Two of these honorary instances of Comparability, (7) and (10), will play crucial roles in the arguments of sections 2 and 3 , respectively.

\section{2 | PREFERENCE}

The contemporary debate about Comparability originated from an argument against a quite different thesis concerning preference and indifference: 
Rational Preference Completeness Necessarily, if one is rational, then if one has some preferences about $x$ and some preferences about $y$, one either prefers $x$ to $y$, prefers $y$ to $x$, or is indifferent between $x$ and $y$.

(By 'one has some preferences about $x$ ', we mean that one either prefers $x$ to something or prefers something to $x$.) Rational Preference Completeness plays a central role in the canonical axiomatic developments of decision theory. But from the beginning there has been a widespread skepticism. ${ }^{4}$ According to von Neumann and Morgenstern $(1944,630)$, "It is very dubious, whether the idealization of reality which treats this postulate ['the completeness of the individual's system of preferences'] as a valid one, is appropriate or even convenient." Aumann $(1962,446)$ agrees: "Of all the axioms of utility theory, the completeness axiom is perhaps the most questionable. Like others of the axioms, it is inaccurate as a description of real life; but unlike them, we find it hard to accept even from the normative viewpoint." Even authors who accept Comparability seem willing to reject Rational Preference Completeness (e.g., Broome 1991, 92-93).

The most influential argument against Rational Preference Completeness is the small improvement argument, due originally to De Sousa (1974). Consider two alternatives $x$ and $y$ that have very different advantages and disadvantages_-say, careers in very different fields. One has some preferences about these alternatives: for example, one prefers a slightly improved career $x^{+}$(just like $x$ but with a slightly greater salary) to $x$, and similarly one prefers a slightly improved career $y^{+}$ to $y$. According to the argument, one might rationally fail to have any preference between $x$ and $y$, given the differences between the two. But this lack of preference should not be understood as indifference, for if one were indifferent between $x$ and $y$, then one would have to prefer anything preferred to $x$, such as $x^{+}$, to $y .^{5}$ But one might rationally fail to have any preference between $x^{+}$and $y$, given the differences between the two. Thus, according to the argument, one has no preference between $x$ and $y$ but is also not indifferent between them, and this is not irrational.

Though some authors have their doubts about the small improvement argument against Rational Preference Completeness (see, e.g., Gustafsson and Espinoza 2010), it is widely taken for granted that the envisaged pattern of preferences is possible, and indeed that the preferences of actual (possibly irrational) human beings are incomplete-i.e., that Preference Completeness is false:

Preference Completeness Necessarily, if one has some preferences about $x$ and some preferences about $y$, one either prefers $x$ to $y$, prefers $y$ to $x$, or is indifferent between $x$ and $y$.

For example, Bales, Cohen, and Handfield (2014) assert that "incomplete preferences are ubiquitous in ordinary life." And many recent contributions to descriptive decision theory either argue that some agents have incomplete preferences, or simply take for granted that they do and go on to offer models of such agents (Bleichrodt 2007; Eliaz and Ok 2006; Galaabaatar 2013; Mandler 2004, 2005; Ok 2002). We suspect that almost everyone would reject Preference Completeness. Everyone, that is, but us.

As unpopular as Preference Completeness may be, Comparability can be leveraged into a powerful argument in its favour. Of course, 'prefer to' is not the comparative form of any gradable expression, so our arguments for Comparability do not directly bear on Preference Completeness. But they can be brought to bear indirectly by appealing to certain connections between 'prefer' and the sort of gradable expressions to which Comparability applies. Consider: 
Comparative Preference $a$ prefers $x$ to $y$ if and only if $a$ likes $x$ more than $y .{ }^{6}$

Comparative Indifference $a$ is indifferent between $x$ and $y$ if and only if $a$ likes $x$ and $y$ equally.

Both of these principles seem valid to us. But if they are, the validity of Preference Completeness will follow from that of Comparability. For if one has any preferences at all about $x$, then one must either like $x$ at least as much as something or like something at least as much as $x .^{7}$ And the same goes for $y$. So, by the extension of Restricted Reflexivity and Comparability to gradable verbs, one must either like $x$ at least as much as one likes $y$ or like $y$ at least as much as one likes $x$. Either way, by the right-to-left directions of Comparative Preference and Comparative Indifference, one will end up preferring one of these things to the other or being indifferent between them, as the consequent of Preference Completeness requires. ${ }^{8}$

In support of the validity of Comparative Preference and Comparative Indifference, we can point to the fact that speeches like 'She likes the vanilla more than the chocolate, but she doesn't prefer the vanilla to the chocolate', or 'He prefers scuba diving to hang gliding although he likes hang gliding more than scuba diving' seem flatly incoherent. Likewise, 'She likes these two restaurants equally but she's not indifferent between them' sounds bizarre: what more, we might wonder, does the speaker think is required for the agent to be indifferent between options?

In fact, Comparative Indifference isn't really crucial to our argument. Given the principles of the logic of comparatives we laid out in Section 1, Comparative Preference on its own implies:

Preference Negative Transitivity Necessarily, if one does not prefer $x$ to $y$ and does not prefer $y$ to $z$ and has some preferences about $y$, one does not prefer $x$ to $z$.

But opponents of Preference Completeness will also reject this principle: in the small improvement argument, one supposedly doesn't prefer $x^{+}$to $y$ or $y$ to $x$ although one does prefer $x^{+}$to $x$ and has some preferences about $y$.

There is room to fuss about the details of the way we formulated Comparative Preference. For example, the form we used, with 'to', can be used with noun phrases and gerunds, but we need to switch to 'than' if we want ' $x$ ' and ' $y$ ' to stand for infinitival clauses or 'that' clauses. We could also vary the mood of the verbs: 'would prefer' and 'would like' are more natural in some cases. ${ }^{9}$ And finally we could use a different combination of verb and adverb on the right-hand side: instead of 'like more' we could have 'like better', or 'want more', 'desire more strongly', etc. For the purposes of decision theory, where the notion of preference at issue is certainly not limited to affective or hedonic considerations, the versions with 'want' and 'desire' may be more apt, although 'like' also seems flexible enough to admit readings that encompass the relevant non-affective sources of motivation. None of these variations are important for our argument, which requires only that there is some biconditional connecting 'prefers' to some expression in the class to which Comparability applies.

The validity of Comparative Preference can be further supported by the observation that in many languages, the natural translations of English sentences involving 'prefer' use some explicitly comparative adjective, adverb, or verb. For example, here's how you would say 'I prefer tea to coffee' in Irish:

Is fearr liom tae ná caife.

is better with me tea than coffee 
Mandarin:

Bǐ qǐ kāfēi, wǒ gèng xǐhuān chá compare coffee, I more like tea

Hindi:

Mujko coffee chai se adhik pasand hai

For me coffee tea than more pleasing is

and Finnish:

Pidän teestä enemmän kuin kahvista

I like tea more than coffee

Some of these languages do also have non-comparative words that could be used to provide less natural translations of sentences involving 'prefer'. ${ }^{10}$ But Irish at least doesn't seem to have any word like that, while in Finnish it is a recent import. ${ }^{11}$ Of course, there is always the option of saying that the languages in question cannot, or cannot easily, be used to talk about preference. But this sits very oddly with the great explanatory importance ascribed to the notion of preference by the orthodox decision-theoretic tradition: it is hard to believe that some human languages have cut themselves off from something so psychologically fundamental.

If we are right about Preference Completeness (and Preference Negative Transitivity), then the sort of scenario imagined in the small improvement argument must be impossible. We suggest that the appearance to the contrary stems from confusing the lack of any known preference with the lack of any preference. We will have more to say about this at the end of the section.

Some readers may find Preference Completeness so implausible that they prefer to treat our argument in this section as a reductio of Comparability. But this move would have some surprising implications. Most theorists who reject Preference Completeness would also deny the analogous principle for transitivity of preference:

Preference Transitivity Necessarily, if one prefers $x$ to $y$ and prefers $y$ to $z$, one prefers $x$ to $z$.

While the claim that rational people always have transitive preferences has been widely endorsed, discussions of that thesis typically treat it as obvious that at least irrational people can have intransitive preferences. For example, Resnik (1987, 23-4) thinks that "Experiments can easily determine that humans are not always able to have transitive preferences," although "the transitivity conditions characterize the preferences of an ideally rational agent." 12 These theorists would insist that it is possible for an agent to prefer $x$ to $y$ and $y$ to $z$ without preferring $x$ to $z$. But, as we said at the outset of this paper, Transitivity is one of the least controversial principles in the logic of comparative expressions - certainly far less controversial than Comparability. ${ }^{13}$ Given Transitivity and Strict Comparison, Preference Transitivity follows from Comparative Preference. This suggests that readers who find Preference Completeness too incredible to be believed would be better off trying to find a way of resisting the arguments for Comparative Preference that we gave above, rather than attempting to use it as a lever to argue against Comparability. 
There is a conception of preference that may be in conflict with Comparative Preference-one that identifies preferences with behavioural dispositions, along the following lines:

Preferences as Dispositions $a$ prefers $x$ to $y$ if and only if $a$ is disposed to choose $x$ when given a choice between $x$ and $y$.

This seems to be the view of Savage (1954, p. 17). While few these days seem to regard Preferences as Dispositions as unequivocally true, it seems quite common to think that 'prefer' has multiple senses, one of which comes down to behaviour in something like this way (see Hausman 2011, $\S 1.1$. Some proponents of Preferences as Dispositions might reject Comparative Preference, on the grounds that one could like $x$ more than $y$ without being disposed to choose $x$ when given a choice between $x$ and $y$, or could be disposed to choose $x$ rather than $y$ without liking $x$ more than $y .{ }^{14}$ Furthermore, there is a clear conflict between Preferences as Dispositions and Preference Transitivity, since it seems possible for someone to be disposed to choose $x$ in a choice between $x$ and $y$, disposed to choose $y$ in a choice between $y$ and $z$, and yet not disposed to choose $x$ in a choice between $x$ and $z$. And there is a similar conflict between Preferences as Dispositions and Preference Negative Transitivity, since it seems possible for someone to be disposed to choose $x^{+}$ in a choice between $x^{+}$and $x$ without being disposed to choose $x^{+}$in a choice between $x^{+}$and $y$ or to choose $y$ in a choice between $y$ and $x$. Thus proponents of Preferences as Dispositions who accept our logic of comparatives would have to reject Comparative Preference.

The relation between Preferences as Dispositions and Preference Completeness itself is a little less clear, since it depends on the behavioural characterization of indifference (which is not mentioned in Preferences as Dispositions). But one natural suggestion is that someone is indifferent between two things iff anything that she (dis)prefers to one she also (dis)prefers to the other. Given this principle, proponents of Preferences as Dispositions will want to reject Preference Completeness, because it seems possible to neither be disposed to choose $x$ when given a choice between $x$ and $y$, nor be disposed to choose $y$ when given such a choice, without being indifferent between $x$ and $y$-since one might be disposed to choose $x^{+}$when given a choice between $x^{+}$and $x$ but not when given a choice between $x^{+}$and $y$, thus preferring something to $x$ that one does not prefer to $y$.

We doubt that there is any meaning for 'prefer' (or any other piece of psychological vocabulary in ordinary English) that is so tightly tied to behavioural dispositions. ${ }^{15}$ For good reasons, philosophers of mind since around 1960 have been pretty much universally agreed on the failure of the program of analytical behaviourism, which purported to provide necessary and sufficient conditions for psychological properties in behavioural terms. So it is somewhat odd that accounts of preference along the lines of Preferences as Dispositions continue to be treated as a live option in the literature on decision theory. The tradition of functionalism which superceded behaviourism in the philosophy of mind has provided a range of ways of making sense of the idea that there are "constitutive links" between mental states and behavioural dispositions that are more like presumptions that hold in normal cases than necessary and sufficient conditions. However, it is not obvious how one could go about arguing against Preference Completeness or Preference Transitivity from a weakening of Preferences as Dispositions along these lines.

Moreover, even if one is committed to giving some kind of analysis of preference in terms of behavioural dispositions, it may still be possible to argue from Comparability to Preference Completeness. After all, 'disposed' is itself a gradable adjective: an object can be more or less disposed to behave in a certain way, or to behave in a certain way under certain conditions (Manley and Wasserman 2007). As with other gradable adjectives, the positive form ' $x$ is disposed to $\phi$ ' will 
presumably involve a contextually determined threshold. This suggests that if one is in the business of analysing 'prefer' in terms of dispositions, it would be more promising to have the analysans use the comparative form of 'disposed', thereby avoiding the need to tie the analysis to an arbitrary threshold. For example, one might propose the following account:

Preference as Comparative Dispositions $a$ prefers $x$ to $y$ if and only if $a$ is more disposed to choose $x$ than $a$ is to choose $y$ when presented with a choice between $x$ and $y .16$

Presumably those who accept Preference as Comparative Dispositions will want to say the analogous thing about indifference:

Indifference as Equal Disposition $a$ is indifferent between $x$ to $y$ if and only if $a$ is equally disposed to choose $x$ as $a$ is to choose $y$ when presented with a choice between $x$ and $y$.

But in the presence of Comparability, these principles sustain an alternative argument for Preference Completeness. For suppose that $a$ has some preferences about $x$ and about $y$ but neither prefers $x$ to $y$, prefers $y$ to $x$, nor is indifferent between the two. Then $a$ must not be more disposed to choose $x$ as $a$ is to choose $y$ in a choice between them, while also not being equally disposed to choose either of them. But if $a$ has some preferences about $x$ and about $y$, it is surely true that $a$ is at least as disposed to choose $x$ as $a$ is to choose $x$ when presented with a choice between $x$ and $y$, and similarly for $y$. This provides the antecedent for the instance of Comparability for the adjectival phrase 'disposed to choose when presented with a choice between $x$ and $y$ '. So, by appealing to Comparability, we can conclude that the following disjunction is true:

Either $a$ is at least as disposed to choose $x$ as $a$ is to choose $y$ when presented with a choice between $x$ and $y$, or $a$ is at least as disposed to choose $y$ as $a$ is to choose $x$ when presented with a choice between $x$ and $y$.

And given Preference as Comparative Dispositions and Indifference as Equal Disposition, this is equivalent to the consequent of Preference Completeness. ${ }^{17}$

Among those who reject the project of analysing preference in terms of behavioural dispositions, a popular alternative (e.g., Broome 2006; Hausman 2011; Joyce 1999; Wedgwood 2017) is to equate preference with a kind of judgment, endorsing something like:

Preferences as Judgments $a$ prefers $x$ to $y$ if and only if $a$ judges $x$ to be better than $y$.

Given that it seems obvious that there are cases where someone (even someone rational) judges $x^{+}$to be better than $x$ without judging $x^{+}$to be better than $y$ or judging $y$ to be better than $x$, Preferences as Judgments plausibly requires giving up Preference Completeness (and perhaps also Rational Preference Completeness) ${ }^{18}$ Of course, if one reasons in accordance with Comparability and judges $x^{+}$to be better than $x$, one will judge that either $x^{+}$is better than $y$ or $y$ is better than $x$; but in general, it is possible to judge that $P$ or $Q$ without judging that $P$ or judging that $Q$. There is also an apparent tension between Preferences as Judgments and Preference Transitivity, since prima facie someone might judge $x$ to be better than $y$ and $y$ to be better than $z$ while failing to 
make the inference to the conclusion that $x$ is better than $z$. Our arguments from Comparative Preference thus count against Preferences as Judgments and potentially also against many other claims with a similar structure: for example, views that equate preferring $x$ to $y$ with judging $x$ to be preferable to $y$, finding $x$ to be better than $y$, with $x$ 's seeming better to one than $y$, etc. ${ }^{19}$

Even setting Comparative Preference aside, the equation of preferences with judgments does not strike us as well-motivated. ${ }^{20}$ 'I prefer vanilla to chocolate although I'm not sure it's better' certainly doesn't sound incoherent in the way that 'I like vanilla better than chocolate although I don't prefer it' does. ${ }^{21}$ Moreover, as soon as we recognise the possibility of suspension of judgment as regards which of two options is better-as we must, if the judgment theory is to motivate rejection of Preference Completeness - we will be naturally led to think about differences in confidence about which of two options is better, and by how much. Such differences will bring into view a whole new array of reasons to prefer one option to another without judging it to be better. For example, if one has middling confidence that $x$ is much better than $y$, while being sure that $y$ is at most slightly better than $x$, one could naturally end up preferring $x$ to $y$. More generally, we find it strange to suppose that a binary cognitive attitude such as judgment should be foundational for the purposes of (normative or descriptive) decision theory, given that so much of decision theory has been concerned with the kinds of graded attitudes that become important in situations of uncertainty.

If we are right that Preference Completeness is true, then why has it been so widely rejected? The popularity of analyses like Preferences as Dispositions and Preferences as Judgments is part of the story; but the appeal of the small improvement argument does not seem to rest entirely on such theoretical identifications. We suspect that Preference Completeness seems obviously counterexample-prone only when one mistakenly assumes that one's preferential states are luminous in the sense of Williamson (2000, ch. 4)-i.e., that one is always in a position to know one's preference (if any) between two options, or whether one is indifferent between them. It is a familiar phenomenon to be able to detect no preference or indifference between two options (e.g., two different kinds of cuisines for dinner). In the grip of luminosity, the theorist concludes that one has no preference between the options and is not indifferent between them; otherwise, one would know it. Luminosity seems to be a widespread assumption among descriptive decision theorists, such as economists and psychologists, who are looking to explain observed choice behaviour or the reported results of introspection, and among normative decision theorists who expect their normative prescriptions about how to act in situations of uncertainty always to be actionable in a sense that would rule out appealing to any non-luminous factors as inputs. But common sense is very comfortable with the idea that in some cases it is very hard to know which of two options one prefers. Moreover, Williamson (2000, ch. 4) has argued powerfully for the claim that no nontrivial conditions are luminous. Once we remind ourselves of the reasons for thinking that our preferential states are not luminous, it should not seem at all obvious that, in any particular case, one's preferences are incomplete.

\section{3 | CONFIDENCE AND CREDENCE}

Bayesians and many others have found it fruitful to theorise about a relation between people, propositions, and real numbers: a given real number in the unit interval can be a given person's credence in a given proposition, also known as their "degree of belief" in it, or its "subjective probability" for them. This technical terminology is often characterised in a way that links it to the familiar notion of confidence. For example, Savage $(1954,3)$ says that "[P]robability measures the 
confidence that a particular individual has in the truth of a particular proposition"; Titelbaum $(2019,1)$ defines credences as "numerical degrees of confidence". Such characterisations naturally suggest two principles linking the technical use of 'credence' to the ordinary word 'confident':

Credence Existence If $a$ is at least as confident that $P$ as $a$ is that $P$, then there exists a (unique) real number $x$ in the unit interval that is $a$ 's credence that $P$.

Credence/Confidence If there exist real numbers $x$ and $y$ such that $x>y$ and $x$ is $a$ 's credence that $P$ and $y$ is $b$ 's credence that $Q$, then $a$ is more confident that $P$ than $b$ is that $Q$.

Other gradable adjectives we could use in place of 'confident' here include 'certain' and 'sure'. ${ }^{22}$

While Credence/Confidence looks hard to deny, Credence Existence is highly controversial. In the large literature on "imprecise probability" (going back to Keynes 1921), it is a commonplace that, with a few isolated exceptions primarily involving logical truths and gambling setups, real human beings almost never have unique real numbers that are their credences in any propositions. For example:

As many commentators have observed..., numerically sharp degrees of belief are psychologically unrealistic. It is rare, outside casinos, to find opinions that are anywhere near definite or univocal enough to admit of quantification. (Joyce 2010, 283)

But probability theory seems to impute much richer and more determinate attitudes than seems warranted. What should your rational degree of belief be that global mean surface temperature will have risen by more than four degrees by 2080 ? Perhaps it should be 0.75 ? Why not 0.75001 ? Why not 0.7497 ? ... It seems there are many events about which we can (or perhaps should) take less precise attitudes than orthodox probability requires. (Bradley 2019, §1)

[T] here are plenty of circumstances in which we manifest confidence without lending point-valued subjective probability. Indeed this looks to be more the norm than the exception in everyday life. (Sturgeon 2020, 67)

Claims like these are generally treated as obvious starting points in the relevant literature, which focuses instead on the normative question whether it is ever rationally permissible, or even rationally compulsory, to have such "imprecise credence". (The dominant answer seems to be yes on both counts.) The frequent occurrences of words like 'precise' and 'definite' in the literature (as in the above quotes from Joyce and Bradley) might suggest an interpretation on which their claims are not in conflict with Credence Existence. Perhaps some authors in the tradition are merely saying that the word 'credence' and its cognates (e.g., 'degree of belief' and 'subjective probability') are vague, in such a way that there is typically no real number to which ' $x$ 's degree of belief in $p$ ' definitely applies, just as there is no natural number to which 'the least number of hairs one could have without being bald' definitely applies. This claim is consistent with Credence Existence, and should be uncontroversial: outside of logic, mathematics, and perhaps certain parts of physics, almost all words are vague, and it would be naïve to suppose that the technical term 'credence' was introduced in a way that avoided it. However, some authors in the tradition (such as Sturgeon in the above quote) are quite explicit in rejecting Credence Existence. Moreover, many authors 
develop further theories about "imprecise probability" which suggest that they were not just making the banal point about vagueness. For example, they describe alternative abstract objects, such as sets of functions from propositions to real numbers ("representors": van Fraassen (1990)), which are supposed to be able to represent certain states of opinion that are not aptly represented by functions from propositions to real numbers. But if the only problem with the latter was one of vagueness, it is unclear why one would take this to be progress: it would be just as naïve to assume that 'representor' was introduced in such a way as to make expressions like 'the set of values to which the members of $a$ 's representor map proposition $p$, have definite application beyond a few special cases. Moreover, given the popular view that vagueness is a linguistic phenomenon of some sort, the vagueness interpretation makes the popular claim that "imprecise credence" is sometimes rationally required look rather unpromising. On a linguistic picture, the fact that the word 'credence' (as we actually use it) is vague in a certain way in application to a certain person is a highly extrinsic fact about that person. It may be that there is some particular state that is sometimes rationally obligatory, and for which our actual usage does not settle a unique determinate description using the word 'credence': but usage can always be sharpened in a way that resolves what were previously borderline cases, and we should not mistake the highly extrinsic characterisation of the state as one whose classification has not yet been settled for an informative positive characterisation of its nature. For these reasons, we take the dominant position to be that Credence Existence is false, not that it is true but merely vague what our credences are.

Given the widespread rejection of Credence Existence, it is not uninteresting to observe that Comparability generates a lot of pressure to accept Credence Existence. The pressure arises from the undisputed possibility of each rational-valued credence:

Credence Possibility For every rational number $x$ that is non-negative and not greater than 1 , it is possible that for some $a$ and $P, x$ is $a$ 's credence that $P$.

For example, it seems quite apt to characterise someone who is absolutely certain that a ball will be fairly chosen from an urn containing $m$ red balls and $n$ green balls, and takes this into account in the usual way, as having credence $\frac{m}{m+n}$ in the proposition that a red ball will be chosen. None of our authors would dispute this: their objection is to the extension of the same numerical measure to cases in which the available evidence is sparser or more disparate. But by appealing to Comparability together with the seemingly unproblematic Credence/Confidence, we can use these uncontroversial cases of credence as a yardstick to assign a real-valued credence to any any pair of a person and a proposition in which that person at least as confident as she is in that proposition.

To spell this out, let us introduce the following definitions:

$x$ is a [lower/upper] bound on $a$ 's credence that $P:=a$ is [more/less] confident that $P$ than anyone who had credence $x$ in some proposition could be in that proposition.

Using these definitions, we can state the following very plausible sufficient condition for having a credence:

Credence Sufficiency If every non-negative rational number less than $x$ is a lower bound on $a$ 's credence that $P$, and every rational number greater than $x$ and no greater than 1 is an upper bound on $a$ 's credence that $P$, then $a$ 's credence that $P$ is $x$. 
This is motivated by the idea that if a real number $x$ satisfies the antecedent, it does everything we could sensibly demand of a "numerical measure" of $a$ 's degree of confidence that $P$.

In the presence of Comparability, these principles constitute bad news for deniers of Credence Existence. For as we show in the Appendix, Comparability, Transitivity, Strict Comparison, Restricted Reflexivity, Credence Possibility, Credence/Confidence, and Credence Sufficiency jointly imply Credence Existence.

Given Comparability, this argument looks hard to resist. The case for the validity of Transitivity, Strict Comparison, and Restricted Reflexivity is at least as strong as the case for Comparability. And none of the worries about real-valued credence suggests any reason to doubt Credence Possibility or Credence/Confidence. ${ }^{23}$ One author who has raised doubts about Credence/Confidence is Williamson (2018), who argues that "The normal use of the word 'confident' does not fit the ideology of credences". ${ }^{24}$ His idea is that even if, for example, I have moderately higher credence that horse 7 will win the race than that any other horse in the race will win, 'I have no confidence that horse 7 will win' might still be true. He takes this to entail that 'I am more confident that horse 7 will win than that horse 6 will win' is false (despite my higher credence). In response: this 'no confidence' seems analogous to other cases where we treat small quantities as if they were zero, e.g. 'I have no interest in your explanations', 'There is no prospect of his being elected', etc. Our favoured account of this kind of phenomenon turns on the contrast between "coarse-grained" and "fine-grained" contexts, which we mentioned in section 1 . Williamson's 'no confidence' sentences naturally elicit a coarse-grained context, since the conditions for ' $x$ has no confidence that $P$ ' to be true in a fine-grained context are too demanding to be plausibly met. But that does not count against the truth of Credence/Confidence in "fine-grained" contexts (which are natural for comparatives: consider 'If $a$ 's height exceeds $b$ 's height by one micron, $a$ is taller than $\left.b^{\prime}\right) .{ }^{25}$ The remaining option is to deny Credence Sufficiency. But denying this principle seems simply to change the subject from credence understood as a measure of confidence to something else. Proponents of this option urgently owe us some alternative positive conception of what they take having a credence in a proposition to require. And even if they answer this challenge, we can still just use the antecedent of Credence Sufficiency to define some new technical term, say ' $x$ is $a$ 's confidence-number that $P$ ', and continue to theorise using the analogues of Credence Existence and Credence/Confidence for this.

The idea that Credence Existence stands or falls with Comparability for adjectives like 'confident' is not at all new. Opposition to real-valued credence has often been inferred from, or used to motivate, failures of completeness for so-called "comparative probability" relations, which are typically explained using gradable adjectives. A central source for the tradition is Keynes (1921), who argues against Comparability for 'likely':

Is our expectation of rain, when we start out for a walk, always more likely than not, or less likely than not, or as likely as not? I am prepared to argue that on some occasions none of these alternatives hold, and that it will be an arbitrary matter to decide for or against the umbrella. (Keynes 1921, 30)

Koopman (1940), an early proponent of the reduction of numerical probability to something comparative, also takes for granted that his chosen comparative relation gives rise to incomparability. ${ }^{26}$ For explicit rejection of Comparability (or its consequences) for 'confident', see Hawthorne (2009, 59); Schoenfield (2012); Kaplan (1996); Konek (2019); and Byrne (2021). ${ }^{27}$ Bradley (2017) says similar things using 'credible' instead of 'confident'. These authors generally focus on the claim that 
the relevant failures of Comparability can arise even for rational people, while taking it for granted that such failures arise for ordinary, imperfectly rational people.

There are several influential positive accounts of credence which are hard to reconcile with Credence Existence. One example is the time-honoured idea that credences are betting dispositions:

Credences as Betting Dispositions $a$ has credence $x$ that $P$ if and only if $a$ is disposed to accept when offered the chance to buy a bet that costs less than $\$ x$ and pays off $\$ 1$ if $P$, and disposed to accept when offered the chance to sell a bet that costs more than $\$ x$ and pays off $\$ 1$ if $P$.

The left-to-right direction of this principle is already in tension with Credence Existence, since one can plausibly be at least as confident that $P$ as that $P$ without there being any $x$ for which one has both the relevant dispositions. (One could even be stably disposed to refuse all offers to buy and sell bets on whether $P$.) But while Credences as Betting Dispositions may be a useful heuristic, few would accept either of its directions as exceptionless generalisations. ${ }^{28}$

Of course we have no objection if someone wants to treat something like Credences as Betting Dispositions as a stipulative definition of 'credence'. Credence Sufficiency will presumably be false on such a definition. However, it seems unlikely that there are any simple or explanatory generalisations about how credences so defined do or should behave. Credence understood as "numerical degree of confidence" seems like a much more promising topic for systematic theorizing. ${ }^{29}$

Another view that is in tension with Credence Existence takes credences to be (or entail) probability judgments:

Credences as Judgments $a$ has credence $x$ that $P$ if and only if $a$ judges that the probability that $P$ is $x$.

Talk of "probability judgments" is pervasive in the literature on "imprecise probability": e.g. Levi (1974) says his "chief concern is to argue that rational men should sometimes avoid adopting numerically precise probability judgments". (It is unclear to us whether Levi is implicitly accepting Credences as Judgments, or is simply not talking about credence in our sense.) Whatever sense of 'probability' might be in question, Credences as Judgments is prima facie in tension with Credence Existence, since it seems rare for people to make perfectly specific judgments about the value of any real-valued quantity whatsoever. ${ }^{30}$ The tension remains when we replace 'judge' in these biconditionals with other attitude-type expressions like 'believe', 'take', 'regard', 'find'. And it applies whether we are thinking of the principles as elucidating credence in terms of some antecedently understood sense of 'probability', or as elucidating some sense of 'probability' in terms of an antecedently understood notion of credence. ${ }^{31}$

Of course, as with Credences as Betting Dispositions, we have no objection if someone wants to treat something like Credences as Judgments as a stipulative definition of 'credence' in terms of some independently given sense of 'probability'. Credence Sufficiency is plausibly false when 'credence' is so understood. However, we expect that a theoretically fruitful investigation of judgment (whether about probability or any other subject matter) will also need to invoke comparisons of confidence, which capture explanatorily and normatively important differences between cases where there is no difference in what is judged to be the case.

If we are right that Credence Existence is true, then why has it been so widely rejected? As with Preference Completeness, we suspect that Credence Existence seems absurd only when one 
mistakenly assumes that one's degrees of confidence are luminous-i.e., that one is always in a position to know what one's credences are. In the grip of luminosity, one will be apt to mistake the very frequent cases where there is no real number that one knows to be one's credence for cases where no real number is one's credence. ${ }^{32}$ When we remind ourselves that our degrees of confidence are not luminous, it should no longer seem obvious that in any particular case, there is no real number that is one's credence in some proposition.

\section{4 | 'OUGHT’ AND UNIQUENESS}

Even among those who think that rational agents ought to have complete preferences and realvalued credences, it is widely believed that there is significant latitude in what we ought to prefer and what credences we ought to have. More generally, many believe that when an agent has several options - whether those options are actions she might perform, or attitudes she might haveit is often false that there is one particular thing she ought to do, or attitude she ought to have. ${ }^{33}$ This section argues from Comparability against this common view.

Besides Comparability, the central premise we will need is that we ought to do what is best:

Maximising Ought If one can $\phi$, and $\phi i n g$ is better than anything else one can do, then one ought to $\phi$.

When $\phi$ stands for an action, the most salient examples of views that accept Maximising Ought are act consequentialism, according to which one ought to perform one of those acts available whose consequences (or expected consequences) are no worse than those of any alternative, and selfinterest theories of prudence or practical rationality, according to which one prudentially ought to choose some option whose (expected) consequences are not worse for oneself than those of any alternative. But maximising principles are also widely endorsed by philosophers who deny that how good an option is (in the relevant sense) is a matter of its consequences: indeed, such principles are close to dogma for much of contemporary normative theory. Portmore (2019) suggests that "the least controversial normative principle concerning action" is that "you ought to perform your best option", in a sense of 'best option' which needn't coincide with the option which brings about the best outcome. Wedgwood $(2009,512)$ generalises the point to all of the readings of 'ought', not just those of central interest in ethics:

[F]or every kind of 'ought' there is a corresponding kind of 'best' such that what ought to be (in this sense of 'ought') is everything that is necessarily entailed by the best state of affairs (in the corresponding sense of 'best').

Crucially, for Wedgwood, the relevant kinds of goodness can be agent- and time-relative, contrary to standard act consequentialism. Sloman $(1970,387)$ likewise suggests that ' $p$ ought to be the case, but it would be better if $q$ were the case' is contradictory when $q$ is among the contextually relevant alternatives to $p$.

Other philosophers have endorsed analogues of Maximising Ought using comparatives other than 'good'. Similar principles expressed in terms of 'reason' are especially widespread, clearly free of any flavour of consequentialism, and neutral as between ethics and epistemology. Schroeder (2007) and many others hold that one ought to $\phi$ just in case one has most reason to $\phi$, in the sense that one has more reason to $\phi$ than to do anything incompatible with $\phi$ ing. Setiya (2014, 
229) endorses a similar principle using the adjective 'strong': according to him, “ $A$ ought to $\phi$, all things considered, just in case the total reason for him to $\phi$ is stronger than the total reason to do anything else”. Others (e.g., Parfit 2011b) say similar things using 'reason' as a count noun, i.e. that one ought to $\phi$ just in case one's reasons for $\phi$ ing are (collectively) stronger than one's reasons for doing anything else. In the case where $\phi i n g$ is a doxastic state like believing a certain proposition, constructions involving the word 'evidence' often play a similar role, e.g. that one ought to believe that $P$ just in case one's evidence supports believing that $P$ more strongly than any alternative. Even philosophers who depart radically from these widespread conceptions of 'ought' seem to endorse other maximizing approaches-e.g., Finlay's (2014) analysis of 'ought' appeals to maximizing the probability of some proposition. From our point of view these views are not importantly different from Maximising Ought, since all of the expressions in question are among those to which our case for Comparability applies. For example, if Comparability is valid, so is 'If one's total reason for $\phi$ ing and one's total reason for $\psi$ ing are each at least as strong as themselves, then either one's total reason for $\phi i n g$ is at least as strong as one's total reason for $\psi$ ing, or vice-versa', and likewise for 'one has at least as much reason for $\phi$ ing as for $\psi$ ing'.

The combination of Comparability and Maximising Ought generates significant pressure to accept

Uniqueness Almost always, if one must either $\phi_{1}, \phi_{2}, \ldots$, or $\phi_{n}$ and these options are mutually exclusive, one either ought to $\phi_{1}$, ought to $\phi_{2}, \ldots$, or ought to $\phi_{n}$.

For suppose that one must either $\phi_{1}, \phi_{2}, \ldots$, or $\phi_{n}$, and that there is no $\phi_{i}$ such that one ought to $\phi_{i}$. Given Maximising Ought, this implies that there are two options, $\phi_{i}$ and $\phi_{j}$, such that neither of them is worse than any of one's options. Given Comparability, this implies that $\phi_{i}$ and $\phi_{j}$ are equally good. But, given the manifold fine-grained factors that seem to be relevant to the goodness of any given option, and the manifold ways in which small differences with regard to these factors can make for small differences in how good an option is, it would seem to be vanishingly unlikely for all the factors to balance out in the way that would be required for there to be multiple options tied for first place. Indeed, since many of the underlying goodness-determining factors seem to be continuous (e.g. expected number of life-years saved in the case of an action, or $p$-value in the case of a belief supported by a scientific study), it's tempting to think that there should be zero chance of such a dead heat, just as there would be zero chance of two runners in a race crossing the finish line at exactly the same instant. But for our purposes the following vaguer 'almost never' claim will suffice:

No Ties It is almost never the case that one has multiple options that are equally good and at least as good as every other option.

Given Comparability, No Ties implies that one almost always has a unique best option; this claim yields Uniqueness when combined with Maximising Ought.

Uniqueness is very controversial, though of course some philosophers do accept it, or versions of it specific to ethics or epistemology. Act-consequentialists, for example, have generally accepted it (on a moral interpretation of 'ought') as part of a general picture on which morality is extremely demanding. There is also a kind of "rigorism" in the post-Kantian tradition: Fichte (1798/2005, 253) for example maintained that "under the dominion of the moral law there are no indifferent actions". And in epistemology, several authors have defended a doctrine of "Epistemic Uniqueness", according to which "Given one's total evidence, there is a unique rational doxastic attitude 
that one can take to any proposition" (White 2005); presumably this attitude is the one one ought to take. Nevertheless, Uniqueness has been widely rejected in both ethics and epistemology, so it is interesting to find it falling out from an argument from premises as weak and topic-neutral as Maximising Ought and No Ties. ${ }^{34}$

Could one escape the argument by denying No Ties? After all, the reasoning behind this principle seems to generalise to all sorts of comparative adjectives, suggesting that claims of the form ' $x$ and $y$ are equally $F$ ' are almost never true; but people say things like this all the time, and it's not plausible to think that they are in the grip of some sort of pervasive error. As we have discussed, our favoured account of this phenomenon is a contextualist one, on which comparative adjectives typically admit "coarse-grained" readings that set undemanding standards for "equally $F$ ' and demanding standards for 'more $F$ than', as well as "fine-grained" readings that work the other way round. 'Ought' also seems, famously, to be context-sensitive (Kratzer 2012; von Fintel and Iatridou 2008; Wedgwood 2006, 2007; Bradley 2021; Finlay 2014; Saint Croix and Thomason 2014; Silk 2014, 2013; Cariani 2013; Carr 2015; Bronfman and Dowell 2018; Chrisman 2015; Worsnip 2019). So it is entirely in the spirit of our approach to say that 'ought' also admits corresponding coarse- and fine-grained readings, where the argument for Uniqueness only goes through on the fine-grained readings. However, this way of resisting the blanket application of the argument has a rather deflationary character. Fine-grained and coarse-grained contexts are not on a par: the former are stricter than the latter, and are more appropriate the more careful we want to be. Expressions like 'strictly speaking' push us to a fine, or at least finer-grained resolution of this form of context-sensitivity: strictly speaking even a micron's difference in height is enough to make one person taller than another, so strictly speaking it is vanishingly unlikely that any given group contains two people who are equally tall. Insofar as we treat Maximising Ought as a constraint on theorising, we will thus be forced to say that strictly speaking, there is almost always a single thing one ought to do.

Since we are taking Comparability for granted in this paper, the other possible way out of the argument is to give up Maximising Ought. This is not an easy option to make sense of: sentences like 'If it's your best option, you ought to take it' have a ring of analyticity. However, it might be suggested that we can do justice to this impression of triviality without accepting Maximising Ought, by leaning on the ideology of vagueness. Since defenders of Comparability typically see vagueness where others posit incomparability, it is natural for us to consider weakening Maximising Ought by strengthening the comparative 'better' in the antecedent to something like 'definitely better'. This weaker principle leaves it open that in a case where one has two options both of which are definitely better than all one's other options, and neither of which is definitely at least as good as the other, neither option is such that one ought to take it (even though one of them is in fact better than the other). And the truth of the weaker principle might help to explain away the initial plausibility of the stronger one, analogously to how some have tried to explain away the appeal of 'If someone with $n-1$ hairs is bald, someone with $n$ hairs is bald' by reference to the truth of 'If someone with $n-1$ hairs is definitely bald, everyone with $n$ hairs is bald'.

The idea that facts about vagueness and definiteness have the normative significance claimed by this proposal cries out for explanation. If $\phi$ ing is better than every alternative but not definitely better, what stops $\phi$ ing from being what you ought to do? It's easy to see why it should not definitely be the case that you ought to $\phi$, since $\phi$ ing is not definitely your best option. But this is compatible with its being the case that you ought to $\phi$. The presumption should be that you ought to $\phi$ if $\phi$ ing is your best option, whether or not it is definitely your best option. To overcome this presumption, there must be a very good explanation, in terms of some feature of vagueness, of the fact that cases where your best option isn't such that you ought to take it only arise when 
it isn't definitely your best option. For example, many philosophers think that vagueness blocks knowledge: if it is vague whether $P$, no-one knows that $P .{ }^{35}$ However, we take it to be a commonplace that in some cases, one ought to do something even though one cannot know that one one ought to do it. The difficulty of knowing about the relative strengths of your reasons may be a good excuse for not doing something, but it does not seem sufficient to render it false that you ought to have done do it. ${ }^{36}$ Another proposed explanation might be the insistence (which we have heard voiced by some moral philosophers), that it cannot be vague whether you ought to do something. We find such exceptionalism deeply implausible. Moreover, given the phenomenon of "higherorder vagueness" (see Williamson 1994), it seems no more friendly to the weakened version of Maximising Ought than to the original version: if the principle is itself supposed to be non-vague, then in a case where it is vague whether it is vague whether $\phi$ ing is one's best option, it cannot be definitely the case that one ought to $\phi$, and hence cannot be the case; one will thus have an even harder time making sense of the initial appeal of Maximising Ought.

So, it's worth seeing if we can learn to live with Uniqueness. Those who find it unacceptable will be tempted to invoke the concept of permissibility, insisting that there are many cases where people have multiple options that are in the relevant way (e.g. morally or rationally) permissible. Many philosophers are in the habit of treating 'ought' and 'permissible' as duals, as 'necessarily' and 'possibly' are treated in standard modal logic and seem to be in English: 'you ought to $\phi$ ' is treated as equivalent to 'it is not permissible for you not to $\phi$ ', and 'it is permissible for you to $\phi$ ' as equivalent to 'it is not the case that you ought not to $\phi$ '. ${ }^{37}$ Given duality, the claim that there is almost always a unique thing we ought to do is equivalent to the following claim:

Unique Permissibility Almost always, if one must either $\phi_{1}, \phi_{2}, \ldots$ or $\phi_{n}$ and these options are mutually exclusive, at most one of them is permissible.

In a slogan: "Everything that is not forbidden is compulsory." 38 The idea seems offputtingly harsh. While it is not so radical as to be indefensible (e.g. by certain act-utilitarians and other kinds of rigorists), it is drastic enough for that consequence to present a serious challenge to those views.

Fortunately for us, 'You ought to $\phi$ ' does not appear to entail 'It is impermissible for you not to $\phi$ '. 'Ought' and 'should' are what are called "weak deontic modals", as opposed to strong deontic modals like 'must', 'have to', 'obligated to', etc. (von Fintel and Iatridou 2008; Silk 2013). And weak deontic modals are not interchangeable with their strong cousins: speeches like 'You ought to do it, but you don't have to' and 'Although parking there would be permissible, you should park somewhere else' sound perfectly fine (White 1968; Sloman 1970; McNamara 1990). 'Permissible' does seem to be dual to 'obligatory': it can't be permissible for you to $\phi$ when it's obligatory for you not to $\phi$, or impermissible for you to $\phi$ when it's not obligatory for you not to do so. But prima facie 'you ought to do this' seems a far less bold commitment than 'you are obligated to do this' or 'it is obligatory for you to do this'. A further piece of evidence for this distinction is the fact that 'ought', but not 'obligated to', exhibits neg-raising behaviour. For example, 'I don't think you ought to eat the tuna' would normally be interpreted to convey 'I think you ought not eat the tuna', unless unusual emphasis is placed on the 'ought'. And the default interpretation of answering 'No' to the question, 'Ought she eat the tuna?' is that she ought not. 'Obligated to' exhibits no such behaviour.

The fact that 'ought' is subject to neg-raising can in fact be used to motivate Uniqueness in a way that is completely independent of Maximising Ought and of Comparability. Neg-raising suggests that we are generally quite comfortable taking on the presupposition that if it's not the case that one ought to do something, one ought to refrain from doing that thing. This is perfectly reasonable if Uniqueness is true; on the other hand, if situations where there is no unique thing one 
ought to do were as common as we take situations where one has several permissible options to be, such Uniqueness-friendly presuppositions would be highly problematic. ${ }^{39}$ Similar presuppositions often emerge with embedded questions. When one is confronted with a hard choice-even one of the fraught choices, with disparate considerations pulling in different directions, where opponents of Uniqueness would say that no option is such that one ought to take it-it is natural to describe one's predicament by saying things like 'I'm having trouble figuring out which of these options I ought to take'. But this seems to presuppose 'There is one of these options that I ought to take', just as 'I'm having trouble figuring out which of these two suspects committed the crime' presupposes 'One of these two suspects committed the crime'. Note that the corresponding presuppositions for strong modals are clearly unacceptable in many cases: 'I'm having trouble figuring out which of these options I'm required to take' invites the response- 'Wait, why do you assume that any of them is required?' These patterns suggest that something like Uniqueness is in the background of much of our ordinary thought and talk about what we ought to do.

Speaking for ourselves, once we realise that Uniqueness does not imply Unique Permissibility, the temptation to think that Uniqueness is obviously false or opposed by "common sense" seems to fall away. There is no clear pre-theoretic reason to want to say that it is common for people to have multiple options each of which is such that it is false that they ought not to do it. The need to use something like 'it is false that...' to force a wide scope negation indicates that we are in the realm of philosophical theory rather than ordinary intuitive thinking: English doesn't seem to have any simple expressions that are plausibly equivalent to 'not ought not'.

Of course, given Comparability, if we want to reject Unique Permissibility, we will be under a lot of pressure to reject the analogue of Maximising Ought for permissibility:

Maximising Permissibility If one can $\phi$, and $\phi$ ing is better than anything else one can do, then it is impermissible not to $\phi .{ }^{40}$

Maximising Permissibility would be equivalent to Maximising Ought if 'ought' and 'permissible' were duals. Given Comparability and No Ties, it implies Unique Permissibility for the same reason that Maximising Ought implies Uniqueness. But Maximising Permissibility does not seem obviously true in the way that Maximising Ought does: 'If $\phi$ ing is the best thing to do, you have to $\phi$ ' and 'If $\phi$ ing is the best thing to do, it would be impermissible for you not to $\phi$ ' feel like stern and substantive demands, nothing like the tautologous-seeming 'If $\phi$ ing is the best thing to do, you ought to $\phi,{ }^{41}$

If Maximising Permissibility is given up, it is natural to wonder how else permissibility might be related to goodness, strength of reasons, or whatever other gradable property plays the role of goodness in Maximising Ought. There must be some such connection if Maximising Ought is true, because strong necessity modals plausibly entail their weak necessity counterparts. If you must (not) do something, then you ought (not) to do it, and it cannot be the case that you ought to do something that you must not do (holding fixed the relevant 'flavor' of deontic modality: prudential, legal, moral, etc.). Given Maximising Ought, this implies that one's best option is always permissible (although other options may be permissible as well). It is tempting to strengthen this to a picture on which any permissible option must be better than any impermissible option: Pummer $(2019,284)$ describes this as a "common assumption" in the literature on supererogation (see also Ferguson and Köhler 2020). But even this is somewhat controversial: in the example of Parfit (2011a, 225), we might think it would be better to risk one's life to save one of two strangers than to refrain from doing so, even though it would be impermissible to do so if one could have costlessly saved the second stranger too, and permissible to refrain (Muñoz 2021). It would be 
desirable to link permissibility and goodness in a more informative way. But we leave that task for further research.

To sum up: since our options are very rarely equally good (on the fine-grained interpretations of 'equally good' that are most normatively relevant), Comparability and Maximising Ought together imply that we rarely have multiple options that are compatible with doing everything we ought. This may seem counterintuitive, because it seems to imply that we rarely have multiple permissible options. But this follows only on the assumption that Maximising Permissibility is true. We see little reason to accept Maximising Permissibility. It derives its appearance of plausibility from the mistaken impression that it is equivalent to Maximising Ought, which is indeed plausible. But these maximising principles are not equivalent: we can accept Maximising Ought while rejecting Maximising Permissibility.

\section{CONCLUSION}

We have drawn three controversial conclusions from Comparability. Everyone has complete preferences. Everyone has real-valued credences. And there is almost always some unique thing we ought to do, prefer, or believe, though we may not be required to do as we ought.

Our arguments for these conclusions relied on some connections between the relevant topics (preference, credence, and what ought to be done) and some relations expressed by naturallanguage comparative (or equative) expressions: 'likes at least as much as', 'is at least as confident that', 'is at least as good as'.

In each case, a salient possible response is to concede our points regarding the ordinary, naturallanguage meanings of 'prefer' and 'ought' and the interpretation of 'credence' tied to the naturallanguage meaning of 'confident', but to claim to be interested not in these notions but rather in some other technical meaning of special interest to decision theory, ethics, or epistemology. We have already considered characterizations of preference and credence that are unfriendly to our arguments from Comparability: for example, views that tie preference to all-or-nothing choice dispositions or evaluative judgments, and views that tie credences to betting dispositions or judgments of probability. These principles could be used to stipulatively redefine 'preference' and 'credence' in such a way as to falsify Preference Completeness and Credence Existence. In the case of 'ought', one might claim to be interested in a notion that just means 'is required' (morally, rationally, or in some other sense), or a notion of 'permissible' that is just defined as the dual of 'ought' in its ordinary sense (i.e., in terms of compossibility with doing everything one ought to do).

We have no objection to the use of stipulative or technical vocabulary. But the recycling of familiar words carries an obvious risk of equivocation: we will be tempted to say things that seem plausible when the words are interpreted in their ordinary senses but that are implausible in their stipulative senses. For example, economists often claim to use 'prefers' in a way that satisfies Preferences as Dispositions, so that they can make inferences about our preferences from observed choice behaviour, but go on to assume that our preferences are intimately tied to our welfare, in ways that are controversial even for the ordinary notion of preference, but completely unwarranted for the technical notion. Similarly, it is much more plausible that our degrees of confidence ought to conform to the probability axioms than that our pattern of dispositions to accept $\$ 1$ wagers ought to do so. Moreover, the offered replacements seem in many cases to be less clear than the familiar notions they are supposed to replace. For example, when 'prefer' is defined in terms of judgments of betterness, or 'credence' in terms of judgments of probability, it's not at all clear how the context-sensitivity of 'judge', 'better', and 'probable' are supposed to be resolved. 
Others will be tempted to set aside the natural-language meanings of the relevant words without offering stipulative definitions to replace them. After all, theoretical terms do acquire meanings without explicit definitions in the sciences (Lewis 1970); a similar process in philosophical theorizing might allow words like 'prefers', 'credence', and 'ought' to take on technical senses on which our central claims about them are false. But the difficulty of this path should not be underestimated. Once the ordinary meanings of the expressions are set aside, it is far from clear that the theoretical role that remains will be anywhere near rich enough to pin down their meanings.

Be that as it may, the original meanings of the relevant expressions are also philosophically interesting. And there is a big disadvantage of hijacking the words and investing them with technical senses: one will then be left without a natural way to discuss important and philosophically central questions about preference, confidence, and what we ought to do. Those, at any rate, are the questions that most interest us, and, as we have argued, Comparability tells us something important about them.

\section{APPENDIX: FROM COMPARABILITY TO CREDENCE EXISTENCE}

This appendix gives a proof of the central thesis of Section 3:

Credence Existence If $a$ is at least as confident that $P$ as $a$ is that $P$, then there exists a real number $x$ in the unit interval that is $a$ 's credence that $P$.

The proof relies on principles of the logic of comparatives discussed in Section 1 (specifically: Strict Comparison, Restricted Reflexivity, Transitivity, Comparability, and their consequence Negative Transitivity), along with three very weak principles about confidence and credence:

Credence/Confidence If there exist real numbers $x$ and $y$ such that $x>y$ and $x$ is $a$ 's credence that $P$ and $y$ is $b$ 's credence that $Q$, then $a$ is more confident that $P$ than $b$ is that $Q$.

Credence Possibility For every rational number $x$ that is non-negative and not greater than 1 , it is possible that for some $a$ and $P, x$ is $a$ 's credence that $P$.

Credence Sufficiency If every non-negative rational number less than $x$ is a lower bound on $a$ 's credence that $P$, and every rational number greater than $x$ and no greater than 1 is an upper bound on $a$ 's credence that $P$, then $a$ 's credence that $P$ is $x$.

where

$x$ is a [lower/upper] bound on $a$ 's credence that $P:=a$ is [more/less] confident that $P$ than anyone who had credence $x$ in some proposition could be in that proposition.

For the purposes of our proof, it will be convenient to restate the definitions of 'lower bound' and 'upper bound' in the language of possible worlds, as follows:

$x$ is a [lower/upper] bound on $a$ 's credence that $P:=$ for every world $w$, possible agent $b$, and proposition $Q$ such that $b$ has credence $x$ in $q$ at $w, a$ is [more/less] confident at the actual world that $P$ than $b$ is at $w$ that $Q$. 
This restatement should be unproblematic given standard assumptions about the metaphysics of possible worlds.

The proof uses two lemmas.

Lemma 1. If rational numbers $y$ and $y^{\prime}$ are respectively a lower and an upper bound on a's credence that $P$, then $y<y^{\prime}$.

Proof. Suppose $y$ and $y^{\prime}$ are rational, $y$ is a lower bound on $a$ 's credence that $P$, and $y^{\prime}$ is an upper bound on $a$ 's credence that $P$. It can't be that $y=y^{\prime}$, since by Credence Possibility there is a possible world $w$ at which some person $b$ has credence $y$ in some $Q$, which would mean that $b$ at $w$ was both more and less confident that $Q$ than $a$ is at the actual world that $P$ : this is impossible by Strict Comparison. Also, it can't be that $y>y^{\prime}$. For by Credence Possibility there are $w, w^{\prime}$, $b, b^{\prime}, Q, Q^{\prime}$ such that at $w, b$ has credence $y$ that $Q$ and at $w^{\prime}, b^{\prime}$ has credence $y^{\prime}$ that $Q^{\prime}$. By Credence/Confidence, $b$ is more confident at $w$ that $Q$ than $b^{\prime}$ is at $w^{\prime}$ that $Q^{\prime}$. Since $y$ is a lower bound on $a$ 's credence that $P, a$ is more confident at the actual world that $P$ than $b$ is at $w$ that $Q$. And since $y^{\prime}$ is an upper bound on $a$ 's credence that $P, b^{\prime}$ is more confident at $w^{\prime}$ that $Q^{\prime}$ than $a$ is at the actual world that $P$. By Transitivity and Strict Comparison, it follows that $a$ is (at the actual world) more confident that $P$ than $a$ is that $P$, which is impossible given Strict Comparison. Hence $y<y^{\prime}$.

Lemma 2. If a is at least as confident that $P$ as a is that $P$, and $y$ and $y^{\prime}$ are rational numbers such that $0 \leq y<y^{\prime} \leq 1$, then either $y$ is a lower bound on a's credence that $P$ or $y^{\prime}$ is an upper bound.

Proof. Suppose for contradiction that $a$ is at least as confident that $P$ as $a$ is that $P$; $0 \leq y<y^{\prime} \leq 1$; $y$ is not a lower bound on $a$ 's credence that $P$; and $y^{\prime}$ is not an upper bound on $a$ 's credence that $P$. Then by the definitions of 'lower bound' and 'upper bound', there exist $w, w^{\prime}, b, b^{\prime}, Q$, and $Q^{\prime}$ such that

(i) $b$ 's credence at $w$ that $Q$ is $y$.

(ii) $b^{\prime}$ 's credence at $w^{\prime}$ that $Q^{\prime}$ is $y^{\prime}$.

(iii) $a$ is not more confident that $P$ at the actual world than $b$ is that $Q$ at $w$.

(iv) $a$ is not less confident that $P$ at the actual world than $b^{\prime}$ is that $Q^{\prime}$ at $w^{\prime}$.

Given Credence/Confidence, (i) and (ii) imply that $b^{\prime}$ is more confident at $w^{\prime}$ that $Q^{\prime}$ than $b$ is at $w$ that $Q$. But given Negative Transitivity and the fact that $a$ is (at the actual world) at least as confident that $P$ as $a$ is that $P$, (iii) and (iv) imply that $b^{\prime}$ is not more confident at $w^{\prime}$ that $Q^{\prime}$ than $b$ is at $w$ that $Q$ : contradiction.

Given these lemmas we can establish Credence Existence. For suppose that $a$ is at least as confident that $P$ as $a$ is that $P$. If there aren't any rational lower bounds on $a$ 's credence that $P$, Lemma 2 implies that every positive rational number $\leq 1$ is an upper bound on $a$ 's credence that $P$, which by Credence Sufficiency implies that $a$ 's credence that $P$ is 0 . Similarly, if there aren't any rational upper bounds, Lemma 2 implies that every non-negative rational number less than 1 is a lower bound, which by Credence Sufficiency implies that $a$ 's credence that $P$ is 1 . Finally, if there are both lower and upper bounds on $a$ 's credence that $P$, the two lemmas jointly imply that the supremum of the set of rational lower bounds on $a$ 's credence in $P$ is identical to the infimum of the set of rational upper bounds of $a$ 's credence in $P$. Call this number $x$. Since every 
rational number less than $x$ is a lower bound on $a$ 's credence that $P$, and every rational number greater than $x$ is an upper bound on $a$ 's credence that $P$, Credence Sufficiency implies that $x$ is $a$ 's credence that $P$.

\section{ACKNOWLEDGMENTS}

Thanks to Johann Frick, Jeremy Goodman, Ben Holguín, Ankit Kansal, Harvey Lederman, Ofra Magidor, Matt Mandelkern, Ralph Wedgwood, Alexis Wellwood, Timothy Williamson, Juhani Yli-Vakkuri, and Snow Zhang.

\section{EN D NOTES}

${ }^{1}$ As explained in Dorr, Nebel, and Zuehl (2021), we state Comparability in this conditional form to avoid commitment to odd disjunctions like 'Either this song is at least as hairy as that song or that song is at least as hairy as this one'. It's worth noting that ' $x$ is at least as $F$ as $y$ ' plausibly carries both ' $x$ is at least as $F$ as $x$ ' and ' $y$ is at least as $F$ as $y$ ' as presuppositions. For example, 'Is this song at least as hairy as the sky?' seems odd in a way naturally explained by presupposition-failure. Thus if Comparability is valid, its consequent also enjoys a certain validity-like status: it must be true when its presuppositions are satisfied.

${ }^{2}$ Proof: Suppose the antecedent of Negative Transitivity is true but the consequent is false: $x$ is more $F$ than $z$. Then by Strict Comparison and Restricted Reflexivity, $x$ and $z$, as well as $y$, are at least as $F$ as themselves. So, given Comparability and Strict Comparison, the antecedent implies that $z$ is at least as $F$ as $y$ and $y$ is at least as $F$ as $x$. So, by Transitivity, $z$ is at least as $F$ as $x$, which by Strict Comparison contradicts the assumption that $x$ is more $F$ than $z$.

${ }^{3}$ While we do not take (1)-(5) to be valid in the strictest sense, we do think that they are "presuppositionally valid": when the presuppositions of the antecedent are satisfied-namely that each of the relevant things is as $F$ as itself-the conditional must be true. For example, 'Grana Padana isn't as good as Parmesan' presupposes (though it does not entail) 'Grana Padana is at least as good as itself and Parmesan is at least as good as itself', and so long as this presupposition is true, (1) must be true. In the case of (1) and (2), it is difficult to see how such presuppositional validity could be explained unless Comparability is valid. In the case of the other three argument-forms, opponents of Comparability could in principle accept the appearances of validity, but only at the cost of drastically restricting the range of cases in which Comparability fails in a way that would undermine the intuitions which are supposed to tell against Comparability, and generate a strong simplicity-based reason for thinking that Comparability holds across the board.

${ }^{4}$ Rational Preference Completeness is not usually formulated in this conditional form, but only because those discussing the consequent of Rational Preference Completeness restrict it to objects that are within the 'field' of the agent's preference relation, which effectively comes to the same thing as the antecedent of Rational Preference Completeness. It should therefore be clear that the doubts expressed below are not driven by the idea that people can rationally fail to have preferences about some things.

${ }^{5}$ This assumes what is often called PI-transitivity: if one is rational, and if one prefers $a$ to $b$ and is indifferent between $b$ and $c$, then one prefers $a$ to $c$. PI-transitivity follows from the transitivity of rational "weak" preference (i.e., 'prefers-or-is-indifferent') on the assumption that one cannot both prefer $a$ to $b$ and be indifferent between them.

${ }^{6}$ The Oxford English Dictionary defines the relevant use of 'prefer' as: 'To favour... in preference or to another; to like better. Also: to choose rather, tend to choose.' We of course have in mind the first meaning, where preference is a psychological state rather than an act of choosing.

${ }^{7}$ This follows from Strict Comparison and the left-to-right direction of Comparative Preference.

${ }^{8}$ As we explain in Dorr, Nebel, and Zuehl (2021), certain sentences that might seem like instances of Comparability admit habitual readings on which they are plausibly false; we deny that they are instances of Comparability properly understood. Sentences of the form ' $a$ likes $x$ more than $y$ ' can be read as habituals tantamount to something like 'Typically, when considering $x$ and $y, a$ likes $x$ more than $y$ '. For our argument for Preference Completeness to work, we must set this reading aside and insist on a non-habitual interpretation of both 'prefers' and 'likes more than', on which they concern the agent's current psychological state: this is the reading of 'prefer' that matters in decision theory, and is the one we are concerned with. 
${ }^{9}$ Note that despite appearances, 'would prefer' and 'would like' are not normally about the psychological state the agent would have been in under some counterfactual circumstances: cf. 'I would prefer my grave to be garlanded with peonies'.

${ }^{10}$ In Mandarin you could also say 'Bǐ qǐ kāfēi, wǒ piān'ài chá'. Likewise, while the natural German translation is 'Ich habe Tee lieber als Kaffee', one can also say 'Ich ziehe Tee dem Kaffee vor'.

11 Thanks to Juhani Yli-Vakkuri for data on Finnish, Harvey Lederman and Snow Zhang for Mandarin, and Ankit Kansal for Hindi.

${ }^{12}$ For the minority view that even rational people can have intransitive preferences, see Fishburn (1991); Anand (2009); Temkin (2012); Rachels (1998).

${ }^{13}$ Though of course Transitivity has its opponents (Temkin 2012; Rachels 1998). For defenses of Transitivity against the arguments of Rachels and Temkin, see Nebel (2018); Broome (2006); Huemer (2013); Pummer (2017); Binmore (2003).

14 Though this move would seem odd for those who accept Preferences as Dispositions as one tenet of a larger behaviourist outlook. Such a theorist would presumably want some account of liking/wanting more in terms of choice dispositions. But, to reject Comparative Preference, they would need to be dispositions other than those supplied by the right-hand side of Preferences as Dispositions. And they would owe us an account of why 'prefers' should be understood in terms of binary choice dispositions but 'wants more' should not.

15 The OED's "tend to choose" meaning is plausibly just the result of applying the habitual interpretation of present tense (which, as explained in note 8 , is not relevant for present purposes) to the "choose" meaning of 'prefer'. It provides no more support to the idea that preference is a matter of one's dispositions than the habitual reading of 'Laurie breaks boards with her hands' provides to the idea that breaking is a matter of one's dispositions.

${ }^{16}$ One could alternatively use 'more strongly disposed', which presumably amounts to the same thing.

${ }^{17}$ Note that this line of argument does not generalize to Preference Transitivity or Preference Negative Transitivity unless Preference as Comparative Dispositions is somehow modified. One modification that would do the job would be to just remove the clause 'when presented with a choice between $x$ and $y$ ': for the good standing of such "stimulus-free" disposition-ascriptions, see Manley and Wasserman (2008, §4).

${ }^{18}$ Indeed, since it is also independently plausible that one could prefer $x^{+}$to $x$ without judging $x^{+}$to be better than $y$ or judging $y$ to be better than $x$, the left-to-right direction of Preferences as Judgments is already enough to generate the tension. This direction would be accepted, for example, by Bradley (2017, ch. 4), who holds a "hybrid" theory on which preference is the conjunction of a judgment with a behavioural disposition.

19 Though some of these verbs are naturally read as "weak" (see note 39 below) in a way that will diminish the tension between Preference Completeness and the analogue of Preferences as Judgments.

${ }^{20}$ Some authors seem to think that if preferences are not behavioural dispositions they must be judgments. For example, Steele and Stefánsson (2016) equate the thesis that preferences are "mental attitudes" with the thesis that they are "considered judgments about whether an option is better or more desirable than another;" likewise, Bradley (2017, ch. 4) treats 'mental attitude' as interchangeable with 'judgment'. We find this conflation mysterious.

${ }^{21}$ We take 'I'm not sure it's better' to entail or implicate 'I don't judge that it is better'. Some may feel that 'I don't think it's better' makes the sentence sound worse, but this is plausibly because 'thinks' neg-raises so that 'I don't think it's better' pragmatically implies 'I think it's not better'.

${ }^{22}$ Observe that given Credence/Confidence, Credence Existence is equivalent to the following principle: if $a$ is at least as confident that $P$ as $b$ is that $Q$, then there exist real numbers $x$ and $y$ such that $x \geq y$ and $x$ is $a$ 's credence that $P$ and $y$ is $b$ 's credence that $Q$. The converse of this would be slightly stronger than Credence/Confidence, since it also implies that identity of credences suffices for being equally confident. We confine our attention to the weaker version in order to allow for the possibility of ultra-fine-grained differences in confidence without differences in credence. For example, perhaps one could be less confident that a certain fair coin will not land heads every day throughout an infinite future than that it either will or will not do this, despite having credence 1 in both propositions. As Koopman $(1940,767)$ puts the thought: "Numerical probability gives but a blurred rendering of the ultimate logical relations between probability and certainty."

${ }^{23}$ It is worth noting the argument would still work if we weakened Credence/Confidence by restricting it to propositions about balls in urns and agents who assign credences to those propositions in the canonical way by learning about the chances, so long as we strengthen Credence Sufficiency accordingly, by inserting the same 
restriction in the definition of 'lower bound' and 'upper bound'. The strengthened version seems just as plausible as the original.

${ }^{24}$ Byrne (2021) endorses Williamson's argument.

${ }^{25}$ Williamson supports his thesis by pointing out that 'Which horse are you most confident will win?' feels to have a false presupposition in the imagined circumstances. But for many adjectives it can seem a bit odd to make comparisons between objects near the bottom of the scale, even when such comparisons have a salient true reading. 'Ordinary headaches are quite unpleasant, but at least they are more pleasant than migraines' has a salient true reading, despite the fact that 'Ordinary headaches are not at all pleasant' seems fine and 'Which is more pleasant, ordinary headaches or migraines?' tends to suggest the the questioner is under a serious misapprehension.

${ }^{26}$ Koopman glosses his primitive as " $p_{1}$ given $p_{2}$ is no more probable than $p_{3}$ given $p_{4}$ ", so that (assuming the validity of double-negation elimination and the inference from 'not more probable' to 'no more probable') the "incomparability" he endorses entails, surprisingly, that it can be simultaneously true that $p_{1}$ given $p_{2}$ is more probable than $p_{3}$ given $p_{4}$ and that $p_{3}$ given $p_{4}$ is more probable than $p_{1}$ given $p_{2}$. While he would have done better to write 'at least as' rather than 'no more than', the slip illustrates how hard it is not to slip into assuming Comparability even when one explicitly rejects it.

${ }^{27}$ Sturgeon $(2020, \S 3.2)$ is more cautious, suggesting that 'more confident than' admits multiple "most-natural generalizations" to states of confidence that do not involve credences, and that counterexamples to Comparability arise on some, but perhaps not all, ways of resolving this indeterminacy.

${ }^{28}$ An exception is Walley (1991), one of the leading exponents of "imprecise probabilities" within statistics, who explicitly accepts betting dispositions are necessary but not sufficient for credences.

${ }^{29}$ A somewhat more promising variant of Credences as Betting Dispositions considers preferences instead of behavioural dispositions. Kaplan (1996) uses a version of this for 'more confident than':

[Necessarily, if you are rational and care only for money, then:] You are more confident that $P$ than you are that $Q$ if and only if you prefer ( $\$ 1$ if $P, \$ 0$ if $\sim P$ ) to ( $\$ 1$ if $Q, \$ 0$ if $\sim Q$ ), and you are equally confident that $P$ and that $Q$ if and only if you are indifferent between ( $\$ 1$ if $P, \$ 0$ if $\sim P$ ) to ( $\$ 1$ if $Q, \$ 0$ if $\sim Q$ ).

Kaplan holds that even if you were rational and cared only for money, there could be a pair of propositions $P$ and $Q$ for which you neither preferred a one-dollar bet on $P$ to one on $Q$ nor were indifferent between them; he concludes that even rational people can be counterexamples to Comparability for 'confident'. Given the argument for Preference Completeness in the previous section, we would deny Kaplan's claim about the possibility of preference incompleteness; this would leave us free to accept Kaplan's principle if we wished. But even setting our argument about preference aside, the case for Kaplan's principle strikes us as much weaker than the case for Comparability.

${ }^{30}$ Credences as Judgments has an analogue for comparative confidence:

Comparative Confidence as Judgment $a$ is more confident that $P$ than that $Q$ if and only if $a$ judges that it is more probable that $P$ than that $Q$.

Assumptions structurally like this are frequent in the literature on comparative confidence. For example, Konek $(2019,273)$ uses 'opinion' and 'plausible' instead of 'judge' and 'probable': “Often I simply lack an opinion about which of two propositions is more plausible. I am not more confident that copper will be greater than $€ 2 / \mathrm{lb}$ in $2025 .$. than I am that nickel will be greater than $€ 3 / \mathrm{lb}$ in $2025 . .$. . Neither am I less confident..., nor equally confident. I simply lack an opinion on the matter.” Cariani, Santorio and Wellwood (2019) defend the surprising combination of Comparability with a variant of Comparative Confidence as Judgment using 'believe' instead of 'judge' and 'likely' instead of 'probable'.

${ }^{31}$ For the former attitude, see Holton (2014), Dogramaci (2018), and Byrne (2021). The latter way of thinking about claims like Credences as Judgments, which is pervasive in the literature on credence, can be seen as a kind of expressivism about (the relevant sense of) 'probability', by analogy with the view that equates judging that lying is wrong with disapproving of lying, and takes this as an elucidation of 'wrong' rather than of 'disapprove'. 
For recent defences, and compositional semantic implementations, see Cariani, Santorio and Wellwood (2019); Yalcin (2012); Rothschild (2012); Moss (2016); Swanson (2016). Most focus on 'probably', but Swanson explicitly considers operators of the form 'there is an $x \%$ chance that'. Rothschild and Moss appeal to states like being such that every member of one's representor maps $P$ to some number greater than 0.5 rather than having a credence in $P$ that is greater than 0.5 ; this avoids the worry that the account requires us to hold implausibly specific judgments about probability, at the cost of making it far less clear that we have any independent grip on the relevant mental states other than as patterns of judgment about probability.

${ }^{32}$ Luminosity assumptions have also been deployed directly against Comparability for 'confident'; for example Hawthorne $(2009,59)$ justifies his rejection of Comparability on the grounds that "Real agents may well be unable to assess their comparative confidence in some pairs of statements".

${ }^{33} \operatorname{Raz}(1999,100)$ calls something like this "the basic belief": "most of the time people have a variety of options such that it would accord with reason for them to choose any one of them and it would not be against reason to avoid any of them." Raz thinks the truth of the basic belief is explained by "incommensurabilities" that violate Comparability. We argue, by contrast, from Comparability to the falsity of the basic belief.

34 There is some precedent for this sort of argument. Dworkin (1978) argues that there is almost always a right answer to hard legal cases from an instance of No Ties applied to legal arguments. Mackie (1977) observes that Dworkin's argument presupposes something like Comparability and offers a "small improvement" style argument against it. In reply, Dworkin $(1978,360)$ concedes that "[his] thesis, that ties will be rare, presupposes a conception of morality other than some conception according to which different moral theories are frequently incommensurate." Our argument generalizes Dworkin's insight to all kinds of options.

${ }^{35}$ Some authors (Dorr 2003; Barnett 2011) oppose the idea that vagueness blocks knowledge. Others (Williamson 1994) endorse a variant view concerning sentences: if sentences $S$ is (extensionally) vague, no-one has knowledge "under the guise of" $S$. This is prima facie less promising for the explanation we are seeking: why should the question what one knows under the guise of some particular sentence have special deontic significance?

${ }^{36}$ While it is plausible that there are readings of 'ought' for which the agent's epistemic state plays a key role, they do not work in the relevant way: in the example of the miners from Parfit (2011b, 159), it can be true in the relevant sense that one ought to flood both shafts even though one knows that there is more (objective) reason not do so.

${ }^{37}$ For example, according to G. E. Moore $(1912,14)$, “When we say that a man 'ought' to do one particular action, or that it is his 'duty' to do it, we do imply that it would be wrong for him to do anything else." The dominant tradition in deontic logic follows von Wright $(1951,58)$ in equating "the obligatory" with "that which we ought to do": see McNamara and Putte (2021). In the contemporary literature the duality of 'ought' and 'permissible' is still widely presupposed, often without any remark: for example, Taurek $(1977,295)$, in arguing that it is morally permissible ("not immoral") to save one person rather than five, assumes that this is inconsistent with the doctrine that "other things being equal, one ought to save the greater number" (emphasis ours). Other times, the assumption is more explicit: for example, Lord (2017) claims that one ought to $\phi$ just in case one is rationally required to $\phi$.

38 This is the motto of the totalitarian ant colony in White (1958); see also Heinlein (1940).

39 Another verb subject to neg-raising is 'think': 'I don't think it'll rain' seems tantamount to 'I think it won't rain'; 'believe' works similarly. This fact plays a key role in the argument of Hawthorne, Rothschild and Spectre (2016) for the claim that "belief is weak", so that cases where neither of ' $x$ thinks that $P$ ' nor ' $x$ thinks that not- $P$ ' is true are far rarer than, e.g., cases where neither of ' $x$ is sure that $P$ ' nor ' $x$ is sure that not- $P$ ' is true. They suggest moreover that 'think' is context-sensitive, and that the standards can always be made low enough that the only way for 'Either $x$ thinks that $P$ or $x$ thinks that not- $P$ ' is false is for $x$ 's credences in $P$ and non- $P$ to be exactly equal, which is vanishingly unlikely. See Holguín (2021) for a possible semantic implementation.

${ }^{40}$ In an influential discussion of incomparability ("incommensurability"), Raz seems to commit himself to Maximising Permissibility, saying that options which are 'inferior to others' are not among those which are 'eligible' for choice (Raz 1997, 127).

${ }^{41}$ One payoff of this move is that it provides a simple response to the following argument against Comparability. There appear to be cases in which it is permissible to choose either of two options $x$ and $y$, even though choosing $x$ would be impermissible if there were some third alternative $x^{+}$that was slightly better than $x$. On the assumption that the addition of $x^{+}$need not affect the goodness of $x$ or $y$, one could argue from Maximising Permissibility to the falsity of Comparability. Since we reject Maximising Permissibility, we can allow that this 
pattern of permissibility facts is possible, while maintaining Comparability. Of course, since we accept Maximising Ought, we have to deny that the analogous pattern of 'not-ought-not' facts is possible (assuming it's true that $x^{+}$can be added without affecting the goodness of $x$ and $y$ ). But since that there isn't a simple and natural way of expressing 'not ought not', we see little intuitive pressure to accept such a possibility. Of course, we may be unwilling to assert of $x$ or $y$ that one ought to take it. But this could be explained in many ways-e.g., in terms of our ignorance, or our recognition of vagueness.

\section{REF E R EN C ES}

Anand, Paul (2009). 'Rationality and Intransitive Preference: Foundations for the Modern View.' In The Handbook of Rational and Social Choice: An Overview of New Foundations and Applications. Ed. Paul Anand, Prasanta K. Pattanaik, and Clemens Puppe. Oxford: Oxford University Press.

Aumann, Robert J. (1962). 'Utility Theory without the Completeness Axiom.' Econometrica 30(3), pp. 445-462.

Bales, Adam, Daniel Cohen, and Toby Handfield (2014). 'Decision Theory for Agents with Incomplete Preferences.' Australasian Journal of Philosophy, 92(3), pp. 453-470.

Barnett, David (2011). 'Does Vagueness Exclude Knowledge?' Philosophy and Phenomenological Research 82(1), pp. $22-45$.

Binmore, Ken and Alex Voorhoeve (2003). 'Defending Transitivity against Zeno's Paradox.' Philosophy and Public Affairs 31(3), pp. 272-279.

Bleichrodt, Han (2007). 'Reference-Dependent Utility with Shifting Reference Points and Incomplete Preferences.' Journal of Mathematical Psychology 51(4), pp. 266-276.

Bradley, Darren (2021). 'Ought-Contextualism and Reasoning.' Synthese, https://doi.org/10.1007/ s11229-020-02918-3

Bradley, Richard (2017). Decision Theory with a Human Face. Cambridge: Cambridge University Press.

Bradley, Seamus (2019). 'Imprecise Probabilities.' In The Stanford Encyclopedia of Philosophy. Ed. Edward N. Zalta. Spring 2019 edition. Metaphysics Research Lab, Stanford University.

Bronfman, Aaron and J. L. Dowell (2018). 'The Language of Reasons and "Ought”.' In The Oxford Handbook of Reasons and Normativity. Ed. Daniel Star. Oxford: Oxford University Press, 85-112.

Bronsther, Jacob (2019). 'Vague Comparisons and Proportional Sentencing.' Legal Theory 25(1), pp. 26-52.

Broome, John (1991). Weighing Goods: Equality, Uncertainty and Time. Oxford: Blackwell.

Broome, John (1997). 'Is Incommensurability Vagueness?' In Incommensurability, Incomparability and Practical Reason. Ed. Ruth Chang. Cambridge, MA: Harvard University Press.

Broome, John (2006). 'Reasoning with Preferences?' Royal Institute of Philosophy Supplements 59, pp. 183-208.

Byrne, Alex (2021). Perception and Probability. Philosophy and Phenomenological Research, https://doi.org/10.1111/ phpr.12768

Cariani, Fabrizio (2013). “Ought' and Resolution Semantics.' Noûs 47(3), pp. 534-558.

Cariani, Fabrizio, Paolo Santorio, and Alexis Wellwood (2019). 'Confidence Reports'. Unpublished manuscript. https://philpapers.org/archive/CARCR-7.pdf

Carr, Jennifer (2015). 'Subjective Ought.' Ergo 2(27), 678-709.

Chrisman, Matthew (2015). The Meaning of 'Ought': Beyond Descriptivism and Expressivism in Metaethics. Oxford: Oxford University Press.

De Sousa, Ronald B. (1974). 'The Good and the True.' Mind 83(332), pp. 534-551.

Dogramaci, Sinan (2018). 'Rational Credence Through Reasoning.' Philosophers' Imprint 18(11).

Dorr, Cian (2003). 'Vagueness Without Ignorance.' Philosophical Perspectives 17, pp. 83-113.

Dorr, Cian, Jacob M. Nebel, and Jake Zuehl (2021). 'The Case for Comparability.' Unpublished manuscript. https://philarchive.org/archive/DORTCF-2.

Dworkin, Ronald (1978). Taking Rights Seriously. Cambridge: Harvard University Press.

Eliaz, Kfir and Efe A. Ok (2006). 'Indifference or Indecisiveness? Choice-Theoretic Foundations of Incomplete Preferences.' Games and Economic Behavior 56(1), pp. 61-86.

Elson, Luke (2017). 'Incommensurability as Vagueness: A Burden-Shifting Argument.' Theoria 83(4), pp. 341-363.

Ferguson, Benjamin and Sebastian Köhler (2020). 'Betterness of Permissibility.' Philosophical Studies 177(9), pp. 2451-2469. 
Fichte, Johann Gottlieb (1978/2005). The System of Ethics: According to the Principles of the Wissenschaftslehre. Ed. and trans. Daniel Breazeale and Günter Zöller. Cambridge: Cambridge University Press.

Finlay, Stephen (2014). Confusion of Tongues: A Theory of Normative Language. Oxford: Oxford University Press.

Fishburn, Peter C. (1991). 'Nontransitive Preferences in Decision Theory.' Journal of Risk and Uncertainty 4, pp. 113-134.

Galaabaatar, Tsogbadral and Edi Karni (2013). 'Subjective Expected Utility with Incomplete Preferences.' Econometrica 81(1), pp. 255-284.

Gustafsson, Johan E. (2013). 'Indeterminacy and the Small-Improvement Argument.' Utilitas 25(4), pp. 433-445.

Gustafsson, Johan E. and Nicolas Espinoza (2010). 'Conflicting Reasons in the Small- Improvement Argument.' Philosophical Quarterly 60(241), pp. 754-763.

Hausman, Daniel M. (2011). Preference, Value, Choice, and Welfare. Cambridge: Cambridge University Press.

Hawthorne, James (2009). 'The Lockean Thesis and the Logic of Belief.' In Degrees of Belief. Ed. Franz Huber and Christoph Schmidt-Petri. Dordrecht: Springer, pp. 49-74.

Hawthorne, John, Daniel Rothschild, and Levi Spectre (2016). 'Belief Is Weak.' Philosophical Studies 173(5), pp. 1393-1404.

Heinlein, Robert A. (1940). 'Coventry.' Astounding Science Fiction 25(5), pp. 56-92.

Holguín, Ben (2021). 'Thinking, Guessing, and Believing.' Philosopher's Imprint. Forthcoming.

Holton, Richard (2014). 'Intention as a Model for Belief.' In Rational and Social Agency: The Philosophy of Michael Bratman. Ed. Manuel Vargas and Gideon Yaffe. Oxford: Oxford University Press, pp. 12-37.

Huemer, Michael (2013) Transitivity, Comparative Value, and the Methods of Ethics. Ethics, 123(2), 318-345.

Joyce, James M. (1999). The Foundations of Causal Decision Theory. Cambridge: Cambridge University Press.

Joyce, James M. (2010). 'A Defense of Imprecise Credences in Inference and Decision Making.' Philosophical Perspectives 24(1), pp. 281-323.

Kaplan, Mark (1996). Decision Theory as Philosophy. Cambridge: Cambridge University Press.

Keynes, John Maynard (1921). A Treatise on Probability. London: Macmillan.

Konek, Jason (2019). 'Comparative Probabilities.' In The Open Handbook of Formal Epistemology. Ed. Richard Pettigrew and Jonathan Weisberg, pp. 267-348. https://philpapers.org/rec/PETTOH-2

Koopman, B. O. (1940). 'The Bases of Probability.' Bulletin of the American Mathematical Society 46(10), pp. 763-774.

Kratzer, Angelika (2012). Modals and Conditionals: New and Revised Perspectives. Oxford: Oxford University Press.

Levi, Isaac (1974). ‘On Indeterminate Probabilities.' Journal of Philosophy 71(13), pp. 391-418.

Lewis, David (1970). 'How to Define Theoretical Terms.' Journal of Philosophy 67(13), pp. 427-46.

Lord, Errol (2017). 'What You're Rationally Required to Do and What You Ought to Do (Are the Same Thing!)' Mind 126(504), 1109-1154.

Mackie, John (1977). ‘The Third Theory of Law.' Philosophy and Public Affairs 7(1), pp. 3-16.

Mandler, Michael (2004). 'Status Quo Maintenance Reconsidered: Changing or Incomplete Preferences?' The Economic Journal 114(499), F518-F535.

Mandler, Michael (2005). 'Incomplete Preferences and Rational Intransitivity of Choice.' Games and Economic Behavior 50(2), pp. 255-277.

Manley, David and Ryan Wasserman (2007). 'A Gradable Approach to Dispositions.' Philosophical Quarterly 57(226), pp. 68-75.

Manley, David and Ryan Wasserman (2008). 'On Linking Dispositions and Conditionals.' Mind 117(465), pp. 59-84. McNamara, Paul (1990). 'The Deontic Quadecagon.' PhD thesis. University of Massachusetts.

McNamara, Paul and Frederik Van De Putte (2021). 'Deontic Logic.' In The Stanford Encyclopedia of Philosophy.

Ed. Edward N. Zalta. Spring 2021 edition. Metaphysics Research Lab, Stanford University.

Moore, G. E. (1912). Ethics. London: Williams and Norgate.

Moss, Sarah (2016). Probabilistic Knowledge. Oxford: Oxford University Press.

Muñoz, Daniel (2021). 'Three paradoxes of supererogation.' Noûs, 55(3), 699-716.

Nebel, Jacob M. (2018). 'The Good, the Bad, and the Transitivity of Better Than.' Noûs 52(4), pp. 874-899.

Ok, Efe A. (2002). 'Utility Representation of an Incomplete Preference Relation.' Journal of Economic Theory 104(2), pp. 429-449.

Parfit, Derek (2011a). On What Matters. Vol. 1. Oxford: Oxford University Press.

Parfit, Derek (2011b). On What Matters. Vol. 2. Oxford: Oxford University Press.

Portmore, Douglas W. (2019). Opting for the Best. Oxford: Oxford University Press. 
Pummer, Theron (2017). 'Spectrum Arguments and Hypersensitivity.' Philosophical Studies, 175(7), 1729-1744.

Pummer, Theron (2019). 'All or Nothing, but If Not All, Next Best or Nothing.' Journal of Philosophy 116(5), pp. 278-291.

Rachels, Stuart (1998). 'Counterexamples to the Transitivity of Better Than.' Australasian Journal of Philosophy 76(1), pp. 71-83.

Raz, Joseph (1997). 'Incommensurability and Agency.' In Incommensurability, Incomparability, and Practical Reason. Ed. Ruth Chang. Cambridge, MA: Harvard University Press.

Raz, Joseph (1999). Engaging Reason: On the Theory of Value and Action. Oxford: Oxford University Press.

Resnik, Michael D. (1987). Choices: An Introdution to Decision Theory. Minneapolis: University of Minnesota Press. Rothschild, Daniel (2012). 'Expressing Credences.' Proceedings of the Aristotelian Society 112, pp. 99-114.

Saint Croix, Catharine and Richmond H. Thomason (2014). 'Chisholm's Paradox and Conditional Oughts.' In F. Cariani, D. Grossi, J. Meheus, and X. Parent (eds.), Deontic Logic and Normative Systems. Dordrecht: Springer, pp. 192-207.

Savage, Leonard J. (1954). The Foundations of Statistics. (Revised edition: 1972) New York: Dover.

Schoenfield, Miriam (2012). 'Chilling out on Epistemic Rationality.' Philosophical Studies 158(2), pp. 197-219.

Schroeder, Mark (2007). Slaves of the Passions. Oxford: Oxford University Press.

Setiya, Kieran (2014). 'What Is a Reason to Act?’ Philosophical Studies 167(2), pp. 221-235.

Silk, Alex (2013). 'Evidence Sensitivity in Weak Necessity Deontic Modals.' Journal of Philosophical Logic, 43(4), pp. 691-723.

Silk, Alex (2014). 'Why ‘Ought' Detaches: Or, Why You Ought to Get with My Friends (If You Want to Be My Lover).' Philosopher's Imprint 14(7).

Sloman, Aaron (1970). “Ought' and 'Better”. Mind 79(315), pp. 385-394.

Steele, Katie and H. Orri Stefánsson (2016). 'Decision Theory.' In Stanford Encyclopedia of Philosophy. Ed. Edward N. Zalta. Winter 2016 edition. Metaphysics Research Lab, Stanford University.

Sturgeon, Scott (2020). The Rational Mind. Oxford: Oxford University Press.

Swanson, Eric (2016). 'The Application of Constraint Semantics to the Language of Subjective Uncertainty.' Journal of Philosophical Logic 45(2), pp. 121-146.

Taurek, John M. (1977). 'Should the Numbers Count?' Philosophy and Public Affairs 6(4), pp. 293-316.

Temkin, Larry S. (2012). Rethinking the Good: Moral Ideals and the Nature of Practical Reasoning. Oxford: Oxford University Press.

Titelbaum, Michael (2019). 'Precise Credences.' In The Open Handbook of Formal Epistemology. Ed. Richard Pettigrew and Jonathan Weisberg. PhilPapers Foundation, pp. 1-55. https://philpapers.org/rec/PETTOH-2

van Fraassen, Bas (1990). 'Figures in a Probability Landscape.' In Truth or Consequences. Ed. Michael Dunn and Anil Gupta. Dordrecht: Springer, pp. 345-356.

von Fintel, Kai and Sabine Iatridou (2008). 'How to Say Ought in Foreign: The Composition of Weak Necessity Modals.' In J. Guéron and J. Lecarme (eds.), Time and Modality. Studies in Natural Language and Linguistic Theory. Dordrecht: Springer, pp. 115-141.

von Neumann, John and Oskar Morgenstern (1944). Theory of Games and Economic Behavior. Princeton: Princeton University Press.

von Wright, G. H. (1951). 'Deontic Logic.' Mind 60(237), pp. 1-15.

Walley, Peter (1991). Statistical Reasoning with Imprecise Probabilities. Dordrecht: Springer.

Wedgwood, Ralph (2006). 'The Meaning of "Ought”. In Oxford Studies in Metaethics, vol. 1. Ed. Russ ShaferLandau. Oxford: Clarendon Press, pp. 127-160.

Wedgwood, Ralph (2007). The Nature of Normativity. Oxford: Oxford University Press.

Wedgwood, Ralph (2009). 'The “Good” and the "Right” Revisited.' Philosophical Perspectives 23, pp. 499-519.

Wedgwood, Ralph (2017). 'Must Rational Intentions Maximize Utility?' Philosophical Explorations 20 (sup2), pp. 73-92.

Wellwood, Alexis (2019). The Meaning of More. Oxford: Oxford University Press.

White, Alan R (1968). 'On Being Obliged to Act.' Royal Institute of Philosophy Supplements. 1, pp. 64-82.

White, Roger (2005). 'Epistemic Permissiveness.' Philosophical Perspectives 19(1), pp. 445-459.

White, T. H (1958). The Once and Future King. London: Collins.

Williams, Robert (2016). 'Angst, Indeterminacy and Conflicting Values.' Ratio 29(4), pp. 412-433.

Williamson, Timothy (1994). Vagueness. London: Routledge. 
Williamson, Timothy (2000). Knowledge and Its Limits. Oxford: Oxford University Press.

Williamson, Timothy (2019). 'Knowledge, Credence, and the Strength of Belief.' In Towards an Expansive Epistemology: Norms, Action, and the Social World. Ed. A. K. Flowerree and Baron Reed. London: Routledge. Worsnip Alex (2019). 'Ought'-Contextualism: Beyond the Parochial, Philosophical Studies 176(11), 3099-3119. Yalcin, Seth (2012). 'Bayesian Expressivism.' Proceedings of the Aristotelian Society 112, pp. 123-160.

How to cite this article: Dorr C, Nebel JM, Zuehl J. Consequences of comparability. Philosophical Perspectives. 2021;35:70-98. https://doi.org/10.1111/phpe.12157 